\title{
Student-led, Community Driven Improvement of the Drinking Supply in a Rural Village in South Africa
}

\author{
Author names: \\ Ethan Heil \\ Junior, Civil and Environmental Engineering \\ University of Virginia \\ Charlottesville, VA 22903 \\ ekh7a@email.virginia.edu \\ Duncan Nengwenani \\ Graduate, Microbiology \\ University of Venda \\ Thohoyandou, South Africa \\ frantix32@gmail.com \\ Additional Authors \\ Audrey Raedani \\ Senior, Microbiology and Biochemistry \\ University of Venda \\ Thohoyandou, South Africa \\ raidenspa@hotmail.com \\ Gadisi Nthambeleni \\ Senior, Chemistry and Biochemistry \\ University of Venda \\ Thohoyandou, South Africa \\ gadisi@hotmail.com \\ Rachel Brown-Glazner \\ Senior, Mechanical Engineering \\ University of Virginia \\ Charlottesville, VA 22903 \\ rmb9x@email.virginia.edu \\ Veronica Gutierrez \\ Senior, Environmental Thought and Practice \\ University of Virginia \\ Charlottesville, VA 22903 \\ vcg7c@email.virginia.edu \\ Khuthalani Mathoma \\ Senior, Mining and Environmental Geology \\ University of Venda \\ Thohoyandou, South Africa \\ khuthalanicurtis@gmail.com \\ Robert Swap \\ Professor, Department of Environmental Sciences \\ University of Virginia \\ Charlottesville, VA 22903 \\ rjs8g@email.virginia.edu
}

Abstract - This paper presents the extension of a sustainable water purification project conducted by engineering students from a university in South Africa and a university in the United States. Through collaboration with faculty at both universities and a community in rural South Africa, the student team facilitated the repair of a water filtration system installed the previous year. While the team had the specific goal to repair the system, they entered into this commitment with an open-ended approach to problem solving that drew heavily on community engagement and participation. The following paper describes the technical details of the project and the process by which the community was enabled to take the lead in the assessment, design and implementation of a sustainable repair to their water filtration system.

Index Terms - South Africa, water purification, community engagement, service-learning 


\section{INTRODUCTION}

The provision of potable water in developing regions and underserved areas of the world is both a major concern and an objective of international aid agencies, national governments and local communities. This is also the case of communities in the rural provinces of South Africa. In the Limpopo province of South Africa, where the Venda cultural region is located, only 32\% of children have access to clean, potable water and diarrhea is the leading cause of early death for infants and adults alike. ${ }^{\text {i.ii }}$ While the municipal government has installed infrastructure to deliver water to the taps in most Venda communities, the water supply is inconsistent and irregular. As noted by others who have visited the region (Harshfield et al. 2009), communities regularly go many days without any municipal water and have taken it upon themselves to invest in their own water delivery systems. Communities regularly go days without any municipal water and have taken it upon themselves to invest in their own infrastructure. ${ }^{\text {iii }}$

In the Fall of 2007, an engineering team of two students from the University of Virginia (U.Va.) in the United States and two students from the University of Venda (Univen) in northeast South Africa sought to address this issue. The team was brought together through the Southern African and Virginia Networks and Associations (SAVANA) consortium, a framework created to facilitate research, education, and outreach activities related to the environment through the University of Virginia and partner institutions in South Africa.

After conducting independent research with the aid of SAVANA faculty, the team identified a community in the Venda region that had no access to clean drinking water, but had shown initiative to develop their own water system. This community had run hundreds of meters of piping from a source point in a local mountain stream to two 10,000 L community-owned and installed water tanks. From these central storage tanks, water was distributed to the majority of the community via a local piping system. While this community's water distribution system was delivering an adequate volume of water, it was often contaminated with various life-threatening microorganisms, including E. coli, salmonella, and bilharzia (schistosomiasis). ${ }^{\text {iv }}$

After investigating a variety of water filtration systems, the team decided on a slow sand filtration design because it was simple to install and maintain, affordable, and could be constructed from local materials. In the summer of 2008, they collaborated with the community in the construction of this slow sand filtration system.

This paper documents a community driven development project that was led by a student engineering team from the South African University of Venda and the American University of Virginia. Detail is provided regarding technical design, project management, and the process of community engagement.

While this is a technical report, it is also a story of community service, cultural sensitivity and professional collaboration. As a consequence, the paper often adopts a narrative style, telling the story of the project as it unfolds from its early conceptualization, through the process of collaboration and consensus building, to its completion. In so doing, it offers insight into the both the role of theory and the relevance of day-to-day practice in relationship building and community engagement.

\section{Background on Existing Relationships and the Process of Team Development}

An important component of any successful service learning project is the development of a working relationship with the target community and the establishment of trust. The foundational 
relationships that made this project possible were formed through the SAVANA consortium, which has sparked development and research work in the Limpopo Province of South Africa for several years (Swap et al. (2008), Harshfield et al. (2009)). ${ }^{\mathrm{v}, \mathrm{vi}}$ Two core classes offered through the SAVANA program brought the American and African student authors together to plan and implement this project.

The first class was a short January term course entitled "Ethics, Protocols and Practices of International Research." This class is offered at the University of Virginia, with a ratio of about forty percent South African participants and sixty percent American students. The flights and lodging of the South African students are financed through the consortium. Their presence has proven especially important to the course. As students from places where research and development work is conducted regularly, they are able to offer invaluable knowledge and advice for the American students in the class, who are given the task of designing an international research project based on the ethical protocols and practices taught by SAVANA faculty. The pedagogy of the class is based on the three "R's": Relationship, Respect, and Reciprocity. ${ }^{\text {iii }}$

The second core class of SAVANA is a summer study abroad course entitled "People, Culture, and the Environment of Southern Africa," which has developed over the past decade. Offered by the University of Virginia, this course brings together around fifteen American students and five African students for a six week introduction to the complex humanenvironmental relationships in South Africa and Mozambique. The trip is a blend of lectures, field visits and onsite experiential learning activities offered by prominent scholars and community leaders. It focuses on the complexity of scientific and cultural contexts related to human-environmental interactions, the influence of culture and history on these interactions, and the potential role for international research opportunities related to service and outreach.

It should also be noted that involvement in student organizations at each institution, such as the Global Sustainability Club at the University of Venda and Engineering Students Without Borders at the University of Virginia helped to reinforce the lessons learned in the SAVANA program and strengthened student-to-student collaboration on service learning endeavors.

These academic courses gave students from both continents the opportunity to study and learn in new environments. It opened their minds to the value of contrasting cultural perspectives especially pertaining to community engagement. By facilitating cultural exchange opportunities, the courses also equipped each student with the capability to work collectively with students from other countries in a community engagement setting. These preparatory activities, combined with the personal and institutional relationships facilitated by SAVANA over the past decade, have opened up avenues for faculty and student service learning opportunities on both continents. More importantly, the program has provided students the resources and the partners needed to initiate collaborative community projects.

Projects under the SAVANA consortium are student initiated and financed through various grant programs within and outside of the universities. The emergence of the projects are facilitated through the classes mentioned above and through discussions between students who have done projects in the past and students interested in continuing the work in the future. Faculty at partner institutions of SAVANA advise the project teams, but the projects themselves are separate research endeavors not graded in either of the courses. Students are expected to reflect on the research learning experience by writing numerous papers on the project under an independent study program. 
The current project is rooted in the SAVANA consortium. It is SAVANA's fourth collaborative effort in the Venda region (past service learning endeavors are discussed in Harshfield et al. (2009) and Swap et al. (2008)). Like past SAVANA projects, it was able to benefit from and contribute to the deep relationships between Virginian and South African institutions and communities. ${ }^{\text {vii, viii }}$

\section{Project Overview}

\section{Background on Filtration System}

This project advanced the efforts of Harshfield et al. (2009), who successfully installed a slowsand filtration system onto the existing community water system in the summer of 2008 . $^{\text {ix }}$ This filtration system incorporated two aggregate-filled 5,000 L filter tanks, each with a surface area of $2.54 \mathrm{~m}^{2}$. These filter tanks each fed a respective $10,000 \mathrm{~L}$ community storage tank via about 4 $\mathrm{m}$ of $32 \mathrm{~mm}$ diameter pipe (figure 1). In each of these filter tanks, an under-drain system of perforated piping was placed at the base which would collect the water after it had passed through the filtration layers. A permeable cloth was placed over this under-drain to prevent the filtration medium from passing into the water supply. The filtration medium was then layered from the bottom, up with approximately $30 \mathrm{~cm}$ gravel, $65 \mathrm{~cm}$ coarse sand from a locally owned sand pit, and $10 \mathrm{~cm}$ fine sand from the nearby Mutale River bed (figure 2). The premise of this system is that a biological medium will form naturally upon the top layer of fine sand. This layer will break down the organic matter and microorganisms contained in the water, which will then be filtered by the successive layers of sand. The ideal end result is clean water that meets all international drinking water standards. ${ }^{\mathrm{x}}$ xi

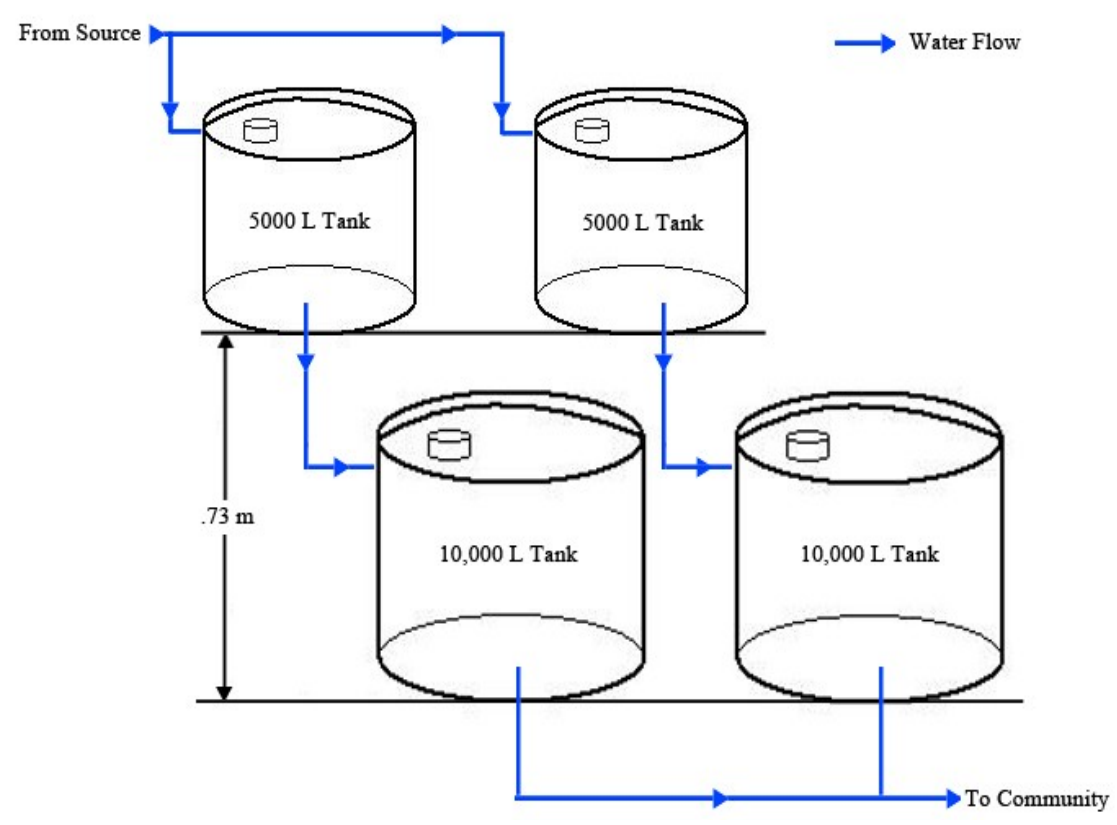

FIGURE 1

Initial Water System Schematic 


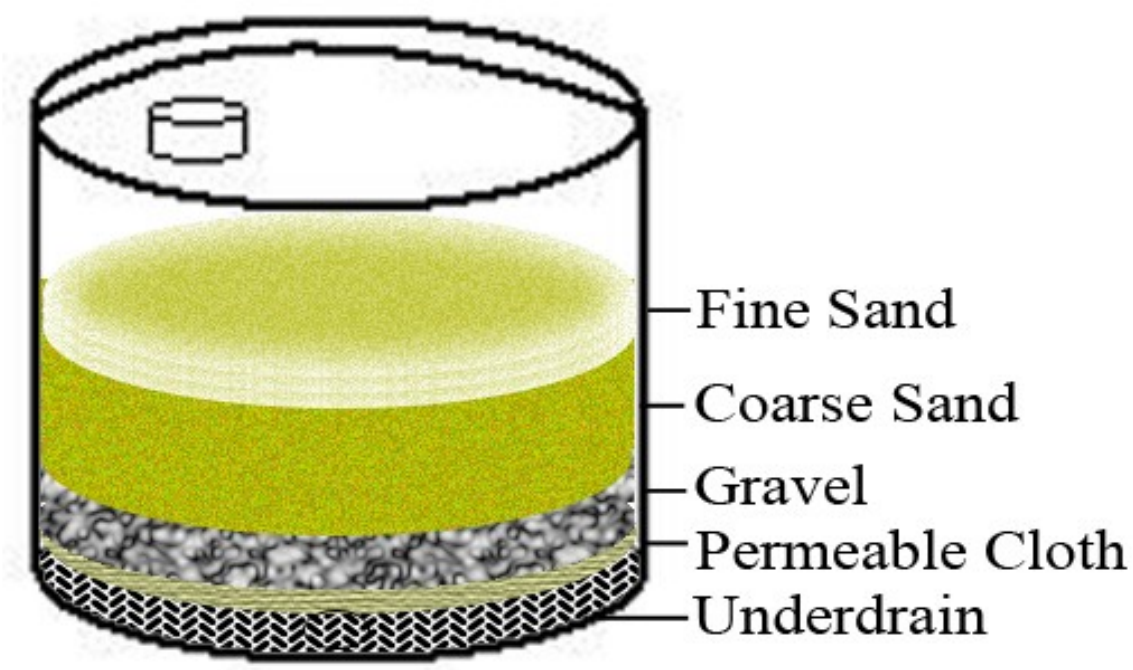

FIGURE 2

Filtration TANK Gradation

Although this system initially performed very well, over the course of several months, the community noticed a decline in the performance of the system and a distinct decrease in flow rate. The flow through the tanks continued to slow until eventually they decided to bypass the filtration tanks altogether. Unfortunately, by bypassing these tanks, the community was resorting once again to a contaminated and potentially unhealthy water source.

One of the main goals of the 2008 team was to collaboratively develop a sustainable, longterm solution that could be maintained by the community. As defined by USAID, such a sustainable solution would ensure "a capacity to continue to deliver services or sustain benefits after the donor's technical, managerial, and financial support has ended". xii Upon hearing that the community had decided to bypass the previously installed system, the team realized such a capacity had hardly been achieved and that without a solid means to address these issues, the project would have ultimately failed.

This scenario is all too common in international development work, especially when external parties install infrastructure that requires even the slightest maintenance or technical knowledge. Often, outside groups will bring a helpful technology to a community without providing the necessary supports systems to maintain a new technology. As a result these once-useful technologies tend to break down and become discarded to the point where they are no longer useful and may even become a burden. Special care must be taken to ensure that technical knowledge and capacity is successfully transferred from the external party and thoroughly understood by community members. ${ }^{\text {xii }}$ The 2008 team had promised that they would provide a sustainable solution and were committed to ensuring that promise was kept.

Failure to keep this promise may also have led to a loss of respect and skepticism about the students' involvement and their institutions, shattering years of collaboration and relationship building. The team did not want this to happen in the community they had worked so closely with, and upon hearing about the issues with the previously installed system, immediately began finding a means to address these concerns. 
Because several of the students were graduating and unable to return to the project site, they sought support from their respective institution's clubs and organizations. Over the Fall semester of 2008 and Spring semester of 2009, they recruited the authors of this article to return to the community and work with them to improve the filters. The 2008 team independently mentored the 2009 team by familiarizing them with the community, the relationships involved, the technical aspects of the filtration system, and their goals for a sustainable solution. The 2008 team also shared all their resources and articles and consistently offered advice on what the next steps might be. The American authors met often with the American members of the 2008 team in person, as did two African authors when they attended the January-term course in the United States in 2009. The African authors also conducted similar meetings among themselves with anyone previously involved in the project and kept in close contact with the American authors through email, VoIP, and phone calls. These close collaborations among all students regardless of year, previous involvement, or geographical location were necessary in order to fulfill the promise of a more sustainable solution.

This project assessed the impact and efficacy of that system and looked to maintain and/or improve upon the original design if need be. After consultation with the community stakeholders and conducting a physical analysis of the water infrastructure system, an implementation plan was developed.

\section{Project Design and Implementation}

As mentioned previously, the foundations for this service learning project have been built upon a history of relationships and trust among students, faculty and community members. The importance of these partnerships had been recognized from the very beginnings of this project and attempts at addressing said relationships have always been the researchers' top priority. Therefore the first step in the project design process was to engage the community and to assess their understanding of the issues with the system through their eyes. Thus, upon the researchers' arrival in Venda the first priority was to arrange a series of meetings.

The first few meetings were not with the community itself, but with other stakeholders that have been involved with the community. The institutional relationship was the first to be addressed as the student researchers from Virginia and Venda met with faculty at Univen. During these meetings, the student research team discussed their expectations, anticipated relationships, and sought advice from the university and specifically their Department of Community Engagement. The strong relationships among this department and the surrounding communities had attracted more than this student led project, and as such the researchers met further with other research teams that would be working in the area during similar times. At this meeting among the researchers and Univen faculty, it was decided that it would be in the community's best interest to pursue a single community meeting in which to address all the researchers' projects and expectations. This way, community members could learn about and consider all projects at the same time. Since the researchers' presentations were integrated into a weekly community meeting, the citizens would not have to take additional time out of their own schedules to find out about the projects.

The researchers then sought the advice of Univen's community liaison, who had played an integral role in the success of the past Univen-U.Va. student projects. He also had an intricate knowledge of the stakeholders involved in this project, having taken coursework at both institutions and being a resident of a neighboring community. He advised us to meet with 
municipality councilor, the local water committee, and the volunteers from past projects before meeting with the community in order to be better prepared to address anticipated community needs. As per his suggestion, such a meeting was organized. The researchers began by explaining their goals as: the repair of the water filtration system that was no longer functioning properly; ensuring the sustainability of this project by addressing community needs and passing on useful and relevant knowledge; to learn from the community by engaging. They then asked the committee and volunteers what they felt the problems with the filtration system were and if they had suggestions to repair it. The community members were very receptive of these questions and several offered their opinions and possible solutions.

The researchers had planned an initial door to door community survey to address the community's perception of the water filtration system, possible flaws, and potential solutions. However, the committee asked us to forgo such a survey and to begin working on repairing the filtration system as soon as possible as that was their main priority. The researchers took these concerns into great consideration and met with Univen faculty to discuss the implications of conducting such a survey. After much deliberation, it was decided that it would be in the community's best interest to forgo the originally planned individual surveys for several reasons. The first of which was the fact that they were expressly asked by the water committee to do so.

The project team viewed this as a great opportunity to allow for increased collaboration with and ownership by the community. A major factor in the decision to omit the surveys was the potential for survey fatigue in the community. This concern was raised once the project team realized that another research group would be conducting surveys addressing similar water related issues at the same time. The authors and Univen faculty mentors felt it would prevent a great deal of confusion to avoid two similar surveys from two outside parties in a short time frame.

Team members then collaborated with the other researchers, Univen faculty and community leaders to develop a community meeting in which all parties could present and discuss the upcoming projects. As a convenience to the community, and to reach as many members as possible, these presentations were incorporated into an existing scheduled weekly community meeting. Project team members explained to the community that they were present to deliver upon the promised commitment to the community and that they were there to enlist the help of the community to collaboratively determine the best solution to the malfunctioning filtration system. Suggestions and insights from the community were solicited as to the nature of the problem and any potential solutions. Once again, the authors noted that the community seemed very receptive to being included in the problem-solving and decision-making process.

After receiving community approval, the authors worked with the community member responsible for maintaining the water system to recruit about a dozen volunteers. With their help and a couple water committee members, a full physical assessment of the filtration system was conducted. Again the authors attempted to take a back seat and let the community members take the lead on this assessment, only stepping in to provide suggestions that they felt might have been overlooked. In fact, the community members were extremely knowledgeable and needed very little guidance.

The assessment resulted in the elucidation of several issues: the inundation and overflow of the filter tanks; the overly fine texture of the sand; the turbidity of the outflow; the loss of pressure head between the filtration storage tanks. All of these concerns were recognized by the community but the latter seemed to be the most dominant issue. This same issue had also been raised during the earlier community meetings when someone mentioned that the outlets of the 
filtration tanks were not high enough to push the water up to the top of the storage tanks. Quite simply, there did not seem to be enough pressure head on the water at the outlets on the base of the filtration tanks to overcome the necessary rise in elevation to the top of the storage tanks. In figure 3, one can see the overall layout of the filtration system. The water enters the light green five thousand liter filtration tanks from at the top and trickles down through the filtration medium to an outlet at the bottom (Figure 3). From there the water is routed down a hill of .73 meters and up about three meters to the inlet of the dark green ten thousand liter storage tanks. It is in this step that the filtration system seemed to be failing, as the water was not passing into the storage tanks. However, the water would pass through the filtration tanks only to pool in the connection tubing without enough pressure to enter the storage tanks. Several community members had suggested that raising the filtration tanks would allow the water to flow more easily into the storage tanks. The authors evaluated such a solution based on their knowledge of fluid mechanics and it seemed this would indeed increase the total energy head of the water at the base of the filtration tanks and allow the water to flow consistently into storage tanks.

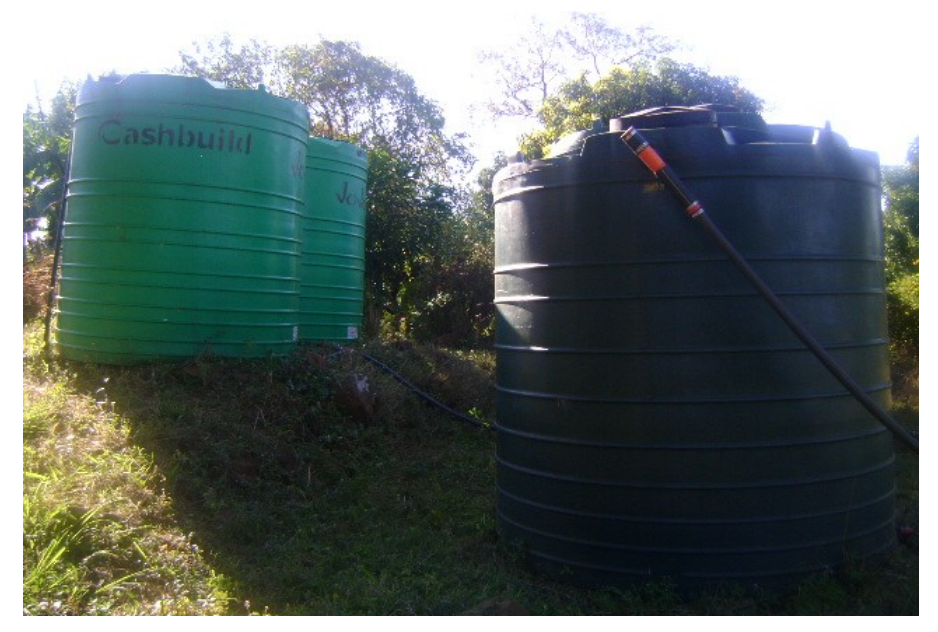

FIGURE 3

Filtration Tanks (light green) on a Hill .73m Above the Storage Tanks (dark green)

We checked our assumptions with faculty at U.Va. and Univen, who affirmed that such a solution should work given the information we had given them. Based on this feedback, the community's suggestions, and the authors' mechanical knowledge, several filter-storage designs were drawn up. Based on these designs, the authors assembled testable prototypes using buckets, tubing, gravel, and coarse and fine sand. The prototypes were constructed in a way to model the actual filter and storage tanks as closely as possible, including the gradation layers of sand and gravel in order to predict the most accurate results. These tests showed that by increasing the elevation of the filters, the flow rate would increase in response. One suggestion we had received from a faculty member involved adding an additional storage tank before the filtration tank to help control the pressure head, but after testing this scenario, we found it did not offer much benefit especially given the added costs (figure 4). 


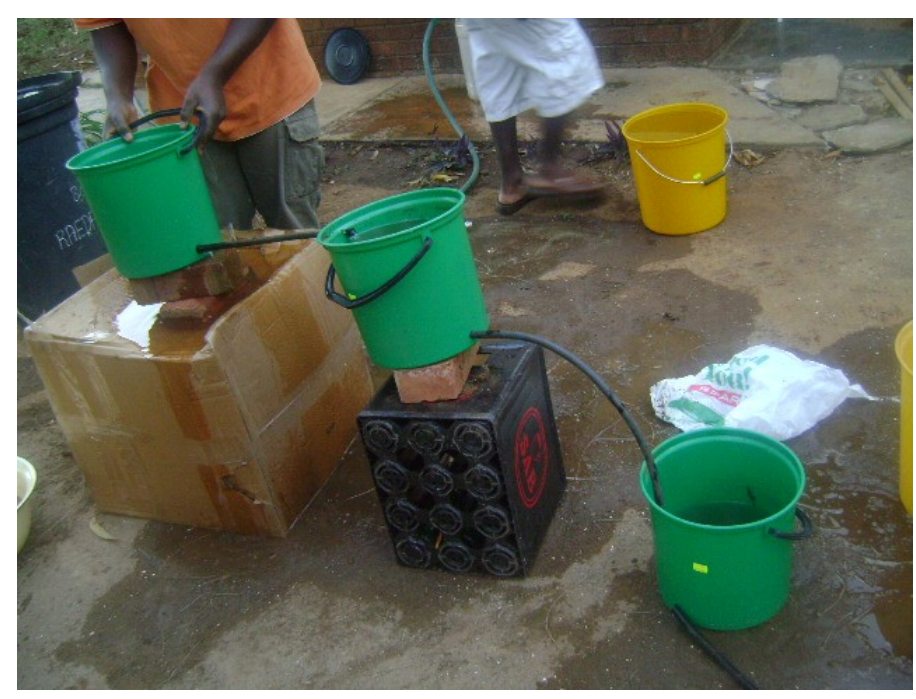

FIGURE 4

Author Testing a Prototype Design With an Additional Storage Tank Before the Filtration TANK

The results from the prototype tests confirmed the earlier hypotheses by the community, faculty advisors, and authors that raising the filter tanks would increase the total energy head and therefore increase flow to the storage tanks. The next step was to devise a sustainable solution based on these results. The authors considered many methods to raising the filter tanks, including moving the tanks uphill, purchasing a stand, or building a platform. Being as the filtration system was only on a slight hill, relocating the filtration tanks farther uphill to achieve the desired increase in head would make it much harder to monitor the system. The system was initially located immediately outside the chief's house, and such relocation would place it quite a ways uphill through rough brush, which would have to be cleared to move the tanks. Also, extra tubing would need to be purchased and a foundation would have to be built on the uneven ground. Purchasing a metal stand may have the most straightforward solution. However, it would have been a solution that would not be possible to replicate or maintain in the absence of ongoing resources. Accordingly, team members thought the most sustainable solution that would both maximize community participation and ownership would be to initiate a hand-built platform construction project. This approach realized the existing volunteer capacity in the village with the involvement of a professional bricklayer with years of experience. Many of the other volunteers were familiar with the process of brick-laying as well, so the authors chose to construct a brick platform upon which to raise the tanks.

Before the platform could be built, the filtration tanks which were filled with several thousand liters of sand and gravel equating to approximately two metric tons each, needed to be moved. The authors and nearly a dozen community volunteers spent about two days emptying the tanks. As the tanks were emptied, care was taken to ensure the graded layers (fine sand, coarse sand, and gravel) were kept in separate piles so they could be replaced accordingly (figure 5). Relationships between the student project team and the community volunteers began to develop during this collaborative effort, enhancing trust and instilling a sense of ownership in the community volunteers. The community volunteers were also provided lunch while they 
contributed their labor. These lunches provided a forum for the authors and volunteers to further develop their relationships and promoted a true collaborative spirit through storytelling, jokes and friendly games of soccer.

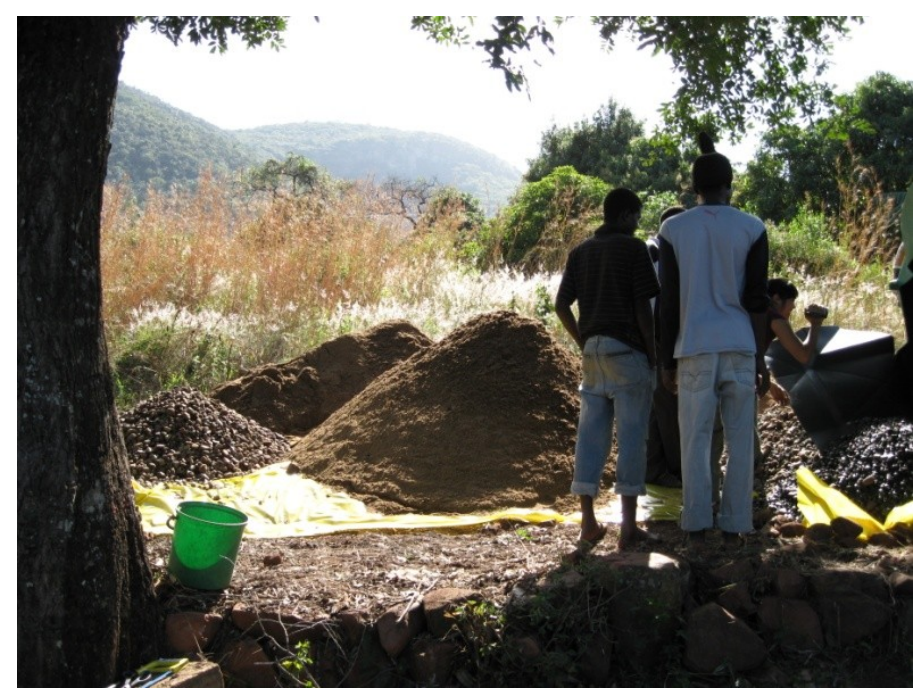

FIGURE 5

Volunteers Separating Filter Tank Contents Into Piles of Gravel, Coarse Sand and Fine SAND

After the filtration tanks were emptied, the platform construction could then begin. First, the materials needed to be obtained. This was inherently an easy task, and was one of the reasons the brick platform was such a suitable alternative. While the authors wanted to ensure community participation in the design and construction of the platform, they also wanted to be certain that the design was sustainable. The authors' goal was to have a design that could be repaired, reconstructed or duplicated using local resources and knowledge. The materials necessary to build the brick platform could either be purchased cheaply at any number of nearby hardware stores (cement, bricks, and reinforcing wire) or gathered freely at the construction site (soil, sand, rocks, and boulders).

When it was time to begin construction, the authors discussed the overall plan and purpose of the platform with the volunteers and then handed over the project to local volunteer craftsmen, who then took the lead on the design and construction. The platform was built using the following procedure. First the platform area was measured and leveled. Sand was then mixed with water and a Portland Cement to create the mortar for the bricks. The head bricklayer led the assembly of three of the four walls with the help of several apprentices, leaving one wall open to make it easier to add the initial heavy fill. The fourth wall was constructed after the middle was filled with enough sufficiently sized boulders and large rocks and the rectangular perimeter of the platform was completed (figure 6). The more tedious task of filling the platform was carried out once the perimeter had properly cured. The fill was added in layers with increasingly smaller rocks and reinforcing wire. These layers were wetted and tamped often to ensure compaction and reduce sinking after the heavy filters were placed on top (figure 7). A final layer of mortar was placed upon the top layer of tamped soil in order to ensure a consistent and sturdy base. 


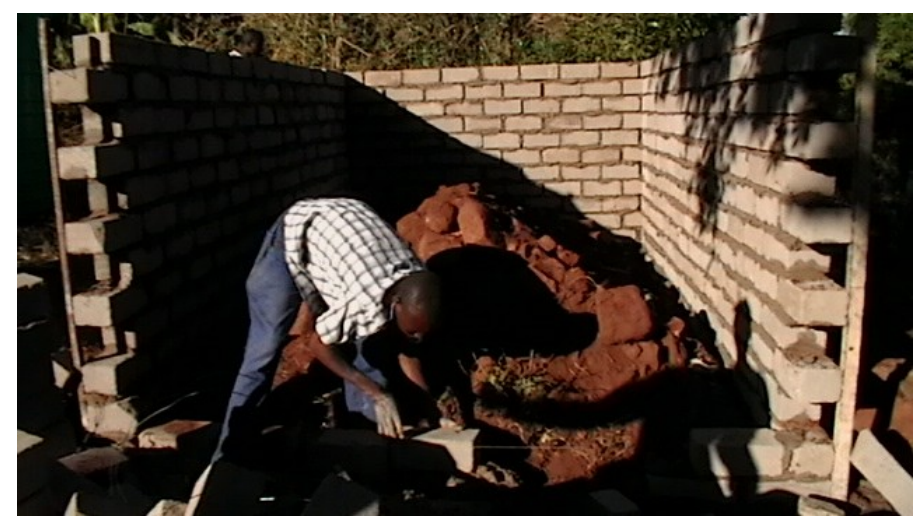

FIGURE 6

Volunteer Assembling Partially Built Wall

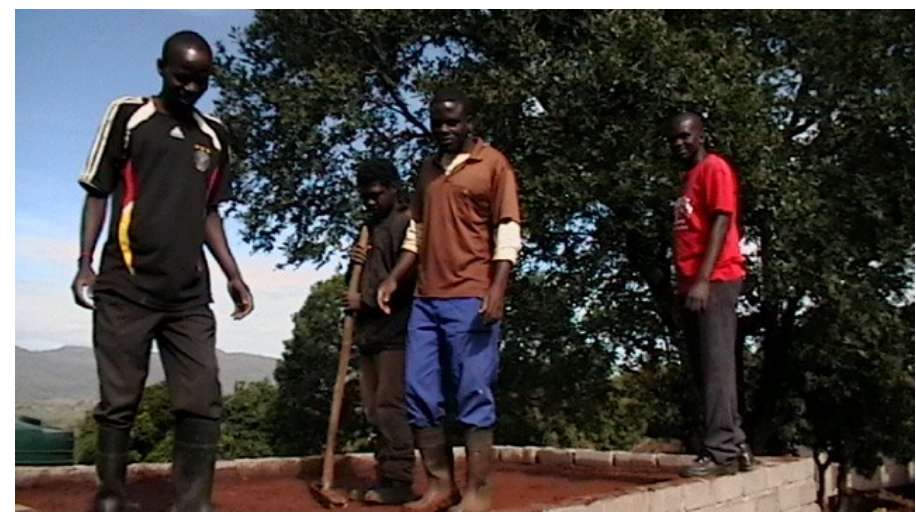

FIGURE 7

Volunteers And Authors Tamping The Final Fill Layer

The platform was allowed to cure for several days before the filtration tanks were placed on top. Gravel and sand were added in the following layers: $28 \mathrm{~cm}$ gravel, $58 \mathrm{~cm}$ coarse sand, and $10 \mathrm{~cm}$ fine sand. About five centimeters of coarse sand was removed from each tank that seemed unnecessary based upon research of other slow-sand water filtration system proportions. It was deemed prudent to remove this sand and that doing so would not significantly reduce the filtration effectiveness but would slightly increase the flow rate. A day after the filtration tanks were filled with the sand and gravel medium, the authors noticed some cracking around the corners of the platform due to the increased weight of the tanks. After conferring with the local tradesmen, modifications to the structure to reinforce the corners with mortar caps, reinforcing wire and concrete nails were undertaken. The platform was given another couple days to cure before the water was introduced to the filtration tanks.

During this time, the community was informed that there would be a reduced water supply over the coming days. This was because the filtration medium had been agitated and it would take several hours for the dirt and turbidity within the tank to be passed. The authors spent three days flushing the tanks from mid-morning to early afternoon. Even during that time, though, the community had access to the water in the storage tanks if they desired it. Only after three days 
were the authors sure that the tanks were sufficiently flushed and no turbidity was recorded. The authors arranged for a water committee member to meet them the next day at the filtration site to lead the reconnection of the water pipes.

While the authors lent a helping hand during this reconnection process, they wanted to make sure it was led by the member of the water committee and that all the volunteers were present. They hoped that this would promote a familiarization and ownership of the system. Figure 8 displays a representative schematic water system and platform dimensions. The authors also took initial flow rate measurements during this time. At this time, the filtration tanks one and two (left and right in figure 3) were measured at a flow rate of .50 and .45 liters per second, respectively. The aggregate flow of these two tanks was approximately equal to the .91 liter per second rate of flow measured at the inflow, representing the fact that the filtration tanks were not slowing the flow rate. Given the combined filter surface area of $5.08 \mathrm{~m}^{2}$ this represented a hydraulic loading rate of about 15,000 liters per day per square meter. The authors would like to note that these measurements were taken before a healthy biological layer had formed on the top sand layer and that the flow rate would likely decrease as this layer formed. This explains why the loading rate is so high compared with desirable range of about 2,500 to 10,000 liters per day per square meter. The authors had also planned on taking water samples at this time, but the only water testing facility in the area was experiencing technical difficulties, so the testing was postponed until a water testing facility could be secured.

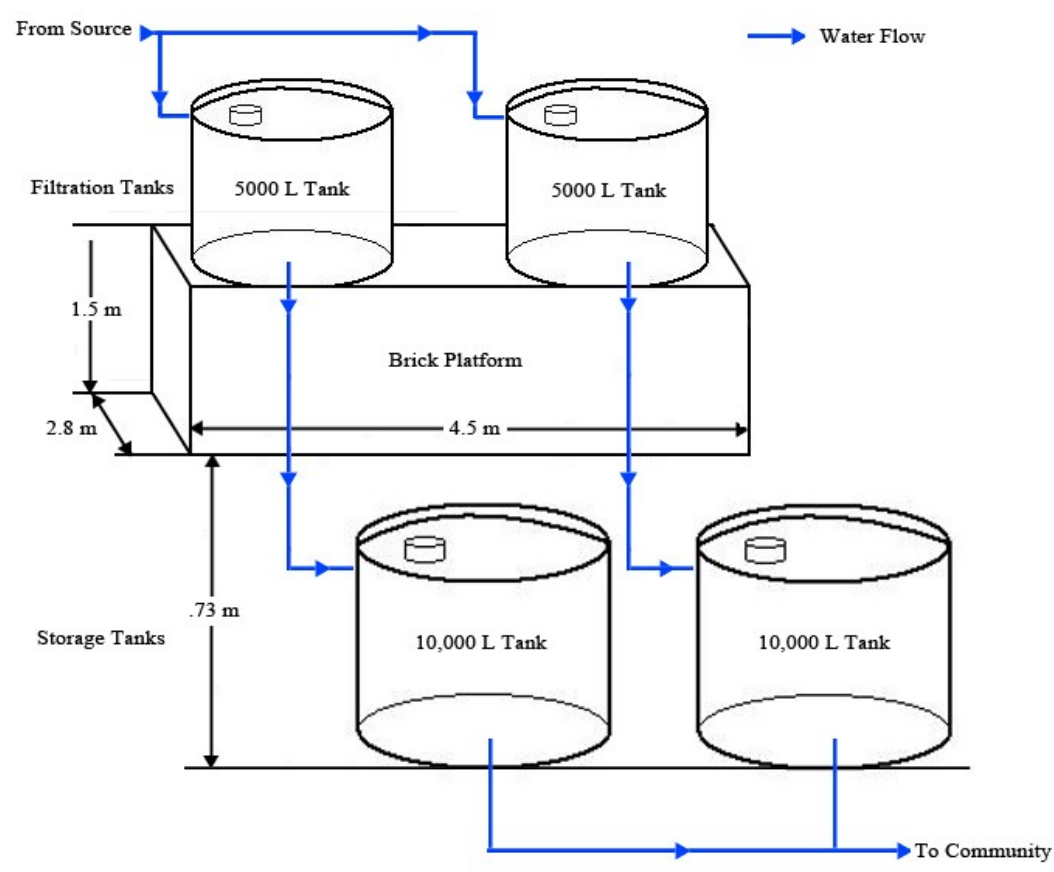

FIGURE 8

Final Water System Schematic Including The Brick Platform and Its Dimensions

The flow rate through the filter tanks is heavily dependent on both the hydraulic conductivity of the sand (which decreases as the biological layer becomes thicker) and the elevation head of 
the water in the tank. Ideally, the elevation head of the water needs to be kept at about 4 to .6 meters above the level of the sand to ensure adequate pressure and to maintain the biological layer. When the hydraulic conductivity and/or inflow is low, there could be a situation where more water is passing through the filters than coming in and this head would not be able to be maintained. To deal with this, the 2008 group added adjustable flow valves to the base of each filter tank to limit the outflow from the filters and maintain a relatively constant head. Also, in order to maintain a favorable conductivity of the filter medium, the biological layer must be occasionally scraped away when it becomes too thick (usually about every 3 to 6 months).

Although these are simple methods for controlling and maintaining the system, they nonetheless still require constant monitoring by the community. Lack of understanding and consistent maintenance is often the first part of a project to fail when an external group leaves, and we were particularly wary about such a situation occurring. Fortunately in this community there was already a committed stakeholder who performed daily maintenance on the system. He had been instructed by the 2008 team as to how to maintain the head level by adjusting the valves and to monitor the decrease in flow rate which corresponded to an increase in biological layer thickness. We spoke with him to ensure he recalled the steps, functions and importance of his duties. He proceeded to explain how he adjusted the valves every morning depending on if the water level was up or down from the previous day and how to scrape off the biological layer. He assured us that these additional duties presented him with no undue burden given that he already monitored the flow rates and amount of water in the storage tank daily to adjust the flow rate to the community.

\section{Assessment of Project Design and Implementation from the Community's Perspective}

Following the construction phase of the project, the authors sought feedback from the community regarding the process of project design and implementation. Since it was decided to forgo the initial surveys, an alternative was sought. During a meeting with the authors, the Director of the Department of Community Engagement at Univen suggested conducting a focus group session modeled after those being done by faculty and students Univen's Rural Development Center. The authors then arranged a meeting with Director of the Center and several students in order to develop a focus group program. With their help, the authors created a program that would organize community members into similar demographic groups. The following groups were chosen, based on the community turn out for the focus groups: the elderly, women, men, volunteers. The Director of the Rural Development Center posed a number of questions that we incorporated into our final focus group discussions. This approach enabled us to assess the efficacy of our project design and implementation process form the community's perspective (see Appendix I). We anticipate that the process by which these questions were chosen would be useful to future service learning teams.

After the completion of the focus groups, the authors organized a volunteer appreciation lunch in order to acknowledge the invaluable help of the volunteers during which each volunteer (builders and cooking staff) was presented a certificate of appreciation and a team t-shirt.

The authors deemed it was next necessary to meet with the community in order to share the authors' experiences, explain the project and express their sincerest gratitude. This presentation was again incorporated into the end of a weekly meeting. The authors explained the whole project process beginning with their original goals, followed by how the decisions were made, the methods of construction, the technical details of the water filtration system, and the focus 
groups. They then asked for those interested to stay and meet at the filtration system for a more in depth explanation and a platform during which they could ask questions and voice concerns.

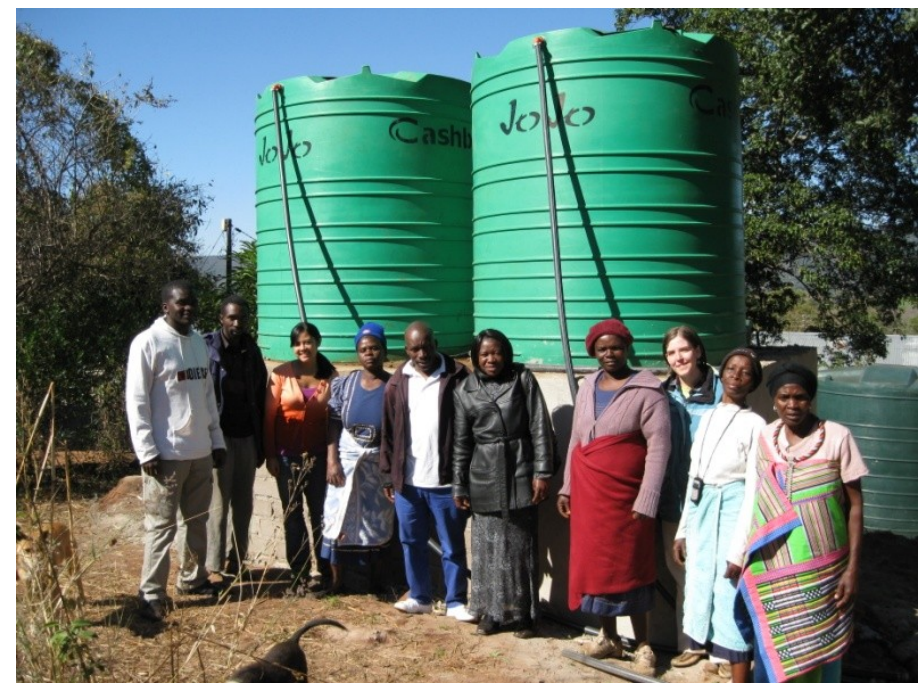

FIGURE 9

\section{Authors And Community Leaders in Front of the Filtrations System}

While the Virginia authors departed shortly after the community meeting, the Venda team members continued to engage with the community and monitor the water filtration system. They took water samples in October of 2009, as shown in Table I. These results show that there is a relatively low coliform count in water sampled at the river source, in the pipes directly before the filters, and at the outlets of both slow sand filters. After both storage tanks, however, coliform counts increase drastically, with 80 counts of coliform per $100 \mathrm{ml}$ found at the outlet of the first storage tank and too many coliforms to count per $100 \mathrm{ml}$ found at the outlet of the second storage tank.

\section{TABLE I}

\begin{tabular}{ll}
\multicolumn{2}{l}{ WATER SAMPLE RESULTS FROM OCTOBER 2009 } \\
\hline Sample & Total coliforms \\
\hline River source & $4 / 100 \mathrm{ml}$ \\
Immediately before filters & $5 / 100 \mathrm{ml}$ \\
After filter 1 & $4 / 100 \mathrm{ml}$ \\
After filter 2 & $2 / 100 \mathrm{ml}$ \\
Storage tank 1 & $80 / 100 \mathrm{ml}$ \\
Storage tank 2 & Too many to count \\
\hline
\end{tabular}

The authors inferred from these results that the site of water contamination was the storage tanks. According to the table, water from the filter tanks is entering the storage tanks with low coliform counts (relatively free of bacteria), but once in the storage tanks, coliform bacteria is multiplying over the course of the day (water continuously sits in the storage tanks and is not consistently and entirely flushed out). The propagation of coliform bacteria in the storage tanks is believed to be the cause of the high coliform count in Table 1. 
Based on these findings, the project's success was limited at best. While both filtration components were assessed and water pressure to the community taps was improved, contaminated water is still being distributed to the village. In this regard, the team's energy towards the improvement of the filtration system means very little until the problem with the storage tanks is addressed. Potential remedies to the storage tank contamination include periodically draining the tanks and cleaning the tanks with bleach and/or treating the water in the storage tanks with chlorine each day to kill the coliform bacteria before they have an opportunity to propagate and multiply.

These suggestions have been relayed to another group of faculty and students from the University of Virginia who will be addressing water system improvements in the same community in the summer of $2010 .{ }^{\text {xiv }}$ With faculty specializing in both health sciences and engineering, they have the capacity to bring additional knowledge and skills to the water quality issues in this community.

\section{Conclusion}

Through the facilitating body of the SAVANA consortium, students from the University of Venda and the University of Virginia were able to collaborate on a service-learning endeavor that ultimately led to the improvement of a water delivery system in a rural village. However, the greatest lessons of the experience were drawn from the process through which this end goal was met.

The authors could have planned and carried out a service-learning project independently, taking little input from the community in the name of efficiency and technical expertise. Rather than carry out the project in this manner, the students sought community consultation and interaction throughout the planning and execution phases. This made the service learning experience a more collaborative effort, encouraging community volunteers to share skills and insights that would have been inaccessible otherwise. By fostering community investment from the beginning, community identification with and ownership of the improved filtration system increased substantially. Additionally, the integral role of the community in this project seemed to elicit an interest and desire on the part of the community to participate in similar endeavors in the future.

Students benefited from this exchange as well. By humbly working alongside the community rather than in service of the community, they were able to learn about the village's water issues from those who knew the community the most - its residents. They also learned how to adapt their initial project idea to the conditions of the work site and the inputs of their community partner.

The most important discovery, however, was the role that relationships between the community and the universities played in the project's success. These relationships, fostered by SAVANA and deepened through this service learning experience, provided a strong foundation for communication and collaboration. They have made sustainable and long-term development work in this region possible. Ultimately, they are the reason this team was able to accomplish what it did, and they are the reason collective work in this region can continue into the future.

\section{ACKNowledgment}

The authors would like to thank their faculty advisors, Vhonani Netshandama from Univen and James Smith and Robert Swap from U.Va. They would also like to thank mentors Joseph 
Francis and Paul Mojapelo from Univen, Garrick Louis from U.Va. and Elias Ramurumo. They greatly appreciated help from the Global Sustainability Club, the water committee, the community volunteers and focus group participants, Lahvelelani Simba, Gugu Glorance, Nkosinathi Shadrack, Tshilidzi Lambani, Sarah Rammbuda, Amanda Brown, and Megan Raymond. Financial support was provided by the Office of University Community Partnerships at the University of Virginia and the Jefferson Public Citizens Program and donations were received by the University of Virginia bookstore.

\section{Appendix I}

Focus group questions are as follows:

1. What are your expectations of outside projects? As community members, what is it that makes an external project acceptable and good to you?

2. What problems have you experienced with past projects? What do you suggest as a solution for the challenges?

3. Think about projects you think were successful and liked by the people. What made them successful?

4. What are some of the signs of their success in their community?

5. What other projects would you like to see being done in your community?

6. How has the experience of working with University (Univen and U.Va.) people been? 


\section{ENDNOTES AND REFERENCES}

${ }^{\text {i }}$ Leatt, A., and Berry, L., "Children's Access to Water, Sanitation, and Electricity," in South African Child Gauge 2006 (2006).

ii Bradshaw, D., Nannan, N., Laubscher, R., Groenewald, P., Joubert, J., Nojilana, B., et al. South African national burden of disease study 2000: Estimates of provincial mortality, (Cape Town: South African Medical Research Council, 2004).

iii Harshfield, E., Jemec, A., Makhado, O., \& Ramarumo, E. (2009). "Water Purification in Rural South Africa: Ethical Analysis and Reflections on Collaborative Community Engagement Projects in Engineering," in International Journal for Service Learning in Engineering Vol. 4, No. 1 (2009).

${ }^{\text {iv }}$ Harshfield et al., "Water Purification in Rural South Africa: Ethical Analysis and Reflections on Collaborative Community Engagement Projects in Engineering," 4.

"Harshfield et al., "Water Purification in Rural South Africa: Ethical Analysis and Reflections on Collaborative Community Engagement Projects in Engineering."

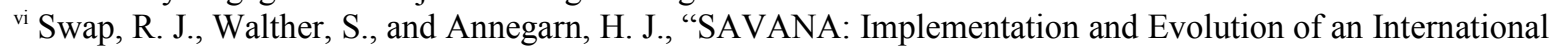
Research and Education Consortium," in IIE Networker, Fall 2008 Special Issue on International Education Trends in Africa, (2008), 34.

vii Harshfield et al., "Water Purification in Rural South Africa: Ethical Analysis and Reflections on Collaborative Community Engagement Projects in Engineering."

viii Swap et al., "SAVANA: Implementation and Evolution of an International Research and Education Consortium" ${ }^{i x}$ Harshfield et al., "Water Purification in Rural South Africa: Ethical Analysis and Reflections on Collaborative Community Engagement Projects in Engineering."

${ }^{x}$ Huisman, L., and Wood, W., Slow Sand Filtration, (Geneva: World Health Organization, 1974), 20-22.

${ }^{x i}$ Bellamy, W. D., Hendricks, D. W., and Logsdon, G. S., "Slow Sand Filtration: Influences of Selected Process Variables," in Journal AWWA, (1985), 63-66.

xii Ostrum, E., Schroeder, L., and Wynne, S., Institutional Incentives and Sustainable Development: Infrastructure Policies in Perspective, (Boulder, Colorado: Westview Pres, Inc., 1993), 13.

xiii Ostrum et al,. Institutional Incentives and Sustainable Development: Infrastructure Policies in Perspective.

xiv Botchwey, N., Boissevain, J. R., Cunningham, T., Louis, G., Learmonth, G., Firehock, K., Terni, C., Swap, R., Spreen, C. A., Samie, A., Reis, J., Netshandama, V., Dillingham, R., "Water and health in Limpopo Province, South Africa: A community-centered collaborative initiative of the University of Venda and the University of Virginia," American Public Health Association, (2009). 